Check for updates

Cite this: RSC Adv., 2017, 7, 28819

Received 31st March 2017

Accepted 11th May 2017

DOI: $10.1039 / c 7 r a 03709 k$

rsc.li/rsc-advances

\section{The growth mechanism of calcareous deposits under various hydrostatic pressures during the cathodic protection of carbon steel in seawater}

\begin{abstract}
C. J. Li (D) ab and M. Du*b
A galvanostatic method was used to study the influence of hydrostatic pressure on the cathodic protection of carbon steel in seawater. The polarization and electrochemical behavior of Q235 carbon steel was studied after being covered with calcareous deposits. Surface analysis was performed to investigate the growth mechanism of the calcareous deposits under various hydrostatic pressures. Although there was no obvious effect of the hydrostatic pressure on the polarization potential decay, the protectiveness of calcareous deposits showed significant variation under the different pressures. The results of electrochemical impedance spectroscopy (EIS) and linear polarization resistance (LPR) indicate that the electrochemical reaction resistance $R_{\mathrm{ct}}$ on the polarized metal surface initially increased with the increasing pressure and then decreased, with a maximum value at $2 \mathrm{MPa}$. The protection factor $F_{\mathrm{p}}$ of the deposits decreased when the pressure was higher than $2 \mathrm{MPa}$. Scanning electron microscopy (SEM) and $\mathrm{X}$-ray diffraction (XRD) analyses illustrated that parts of the calcium lattice positions were substituted by magnesium ions in the initial crystallization of calcium carbonate under $5 \mathrm{MPa}$ pressure or even higher, which resulted in a crystal structure transformation from aragonite to dolomite. The order degree $\delta$ of dolomite decreased under high pressure due to the low free energy of the lattice.
\end{abstract}

\section{Introduction}

Cathodic protection (CP) has been widely used for corrosion control in a marine environment, especially for large static structures such as sub-sea pipelines for oil and gas exploration. In recent years, there has been a substantial increase in energy exploration and production in deep water regions. These expanded operations have involved many new challenges, such as corrosion and materials technology. Since carbon steel is usually the major construction material used for production facilities, good corrosion control and a reliable CP system is essential for safe long-term operation, which is required for the development the deep water resources.

In order to optimize the CP designs for deep water, a thorough understanding of the greater depth environmental effects on the CP process is required. There are significant variations in a series of environmental parameters at great depth, such as the temperature, dissolved oxygen, $\mathrm{pH}$, flow velocity and so on. The variations can severely impact the $\mathrm{CP}$ process and have drawn substantial attention and research. ${ }^{1-8}$ As one of the most influential parameters, hydrostatic pressure is directly proportional to depth and increases by about $0.1 \mathrm{MPa}$ for each $10 \mathrm{~m}$ increase

${ }^{a}$ Weifang University of Science and Technology, Shouguang 262700, P. R. China ${ }^{b}$ The Key Laboratory of Marine Chemistry Theory and Technology, Ministry of Education, College of Chemistry and Chemical Engineering, Ocean University of China, Qingdao 266100, P. R. China.E-mail:ssdm99@ouc.edu.cn in the water depth. However, previous research activity has mostly addressed the other influential variables (e.g. temperature, dissolved oxygen, flow velocity, etc.), still the present stateof-knowledge falls short of the hydrostatic pressure influence on deep water CP. For example, Hartt and the co-workers studied the deep water CP by laboratory simulations and field experiments at a $899 \mathrm{~m}$ Gulf of Mexico site, and it indicated that the current density demand was relatively high in deep water., ${ }^{\mathbf{9} 10}$ This was consistent with the results previously reported by England and Heidersbach. ${ }^{\mathbf{1 1}}$ However, the presented data combined the influences of temperature and pressure and lacked the study on the single factor of pressure. Fischer et al. proposed a semi-empirical formula on the basis of CP electrochemical theory and field experiments, however, the parameter of pressure was not included. ${ }^{\mathbf{1 2}}$

Additionally, calcareous deposits will form on the protected steel surface after CP in seawater. This is because of hydrogen evolution and oxygen reduction reactions:

$$
\begin{gathered}
\mathrm{H}_{2} \mathrm{O}+1 / 2 \mathrm{O}_{2}+2 \mathrm{e}^{-} \rightarrow 2 \mathrm{OH}^{-} \\
2 \mathrm{H}_{2} \mathrm{O}+2 \mathrm{e}^{-} \rightarrow 2 \mathrm{OH}^{-}+\mathrm{H}_{2}
\end{gathered}
$$

Due to the generation of $\mathrm{OH}^{-}$, the magnesium ions will react with $\mathrm{OH}^{-}$and are deposited as brucite of $\mathrm{Mg}(\mathrm{OH})_{2}$ on the steel surface. Further, as the variation of $\mathrm{pH}$ near the steel surface, the inorganic carbonic equilibrium will be disrupted, leading to 
the concentration of carbonate ions and the precipitation of $\mathrm{CaCO}_{3}$.

$$
\begin{gathered}
\mathrm{Mg}^{2+}+2 \mathrm{OH}^{-} \rightarrow \mathrm{Mg}(\mathrm{OH})_{2} \\
\mathrm{Ca}^{2+}+\mathrm{CO}_{3}{ }^{2-} \rightarrow \mathrm{CaCO}_{3}
\end{gathered}
$$

As these non-conductive deposits progressively cover the surface, the flux of dissolved oxygen from seawater towards the steel surface is limited. In addition, the overall rate of the cathodic reaction (eqn (1)) decreases, leading to a reduction in the $\mathrm{CP}$ current density required and consumption the sacrificial anode. ${ }^{13-17}$ Therefore, knowing the formation mechanism and how to promote the quality of the calcareous deposits is important for the design and prediction of a CP system. However, the main attention for the hydrostatic pressure effect on CP has been focused on the variation of current density and there is a lack of studies on the calcareous deposits formation under deep water and high hydrostatic pressure. For example, Hu et al. studied the effect of cyclic hydrostatic pressure on the sacrificial anode $\mathrm{CP}$, while little attention has been devoted to the formation of calcareous deposits on the cathode surface. ${ }^{18}$ Thomason and Fischer suggested that it was not the hydrostatic pressure that causes the compound variation of calcareous deposits in deep water but the temperature and flow velocity, and the growth of calcareous deposits was mainly controlled by the ocean sites and field environments. ${ }^{19}$ Tawns and Oakley studied the CP at a simulated depth of $2500 \mathrm{~m}$ and found that thick but poorly adherent calcareous deposits were formed by high-pressure CP after $30 \mathrm{~d}$, and the protectiveness was not as effective as that found at atmospheric pressure. ${ }^{20}$ While there was a lack of research on the structure and morphology of the calcareous deposits in their presented work.

To date, most studies on the hydrostatic pressure effects on $\mathrm{CP}$ have been devoted to field experiments in deep water. Actually, there are different environmental conditions in different marine regions although at the same depth. Therefore, various conclusions have been drawn for the deep water CP process. Additionally, there are complicated environmental factors in the field sites, which will have a multiple and combined impact on the $\mathrm{CP}$ process. In addition, it is difficult to only study the influence of hydrostatic pressure on CP based on the field experiments results because of the interference of other factors, e.g. temperature and flow velocity. Therefore, the single factor experiment of CP should be performed to eliminate the disturbance of the other environmental factors from hydrostatic pressure in deep water.

In this paper, the effect of hydrostatic pressure on carbon steel CP was studied using a single factor experiment. Specific attention has been focused upon the electrochemical behaviour variation on the carbon steel surface under various hydrostatic pressures after CP, which was studied using EIS and LPR measurements. The growth mechanism of the calcareous deposits was discussed by SEM and XRD analysis, and the crystal structure transformation of $\mathrm{CaCO}_{3}$ under high pressure was investigated. The presented results may be helpful for the supplementation and perfection of CP theory in deep water.

\section{Experimental}

Natural seawater was used in all our experiments, of which the salinity was 32 and $\mathrm{pH}$ was 8.1 from Maidao, a coastal scientific station in Qingdao, China. The seawater was filtered through $0.7 \mu \mathrm{m}$ pore-size glass fiber filters to clear the marine growth before the CP experiments. Carbon steel Q235 was used as the working electrode, with an approximate composition (in weight $\%$ ) of: $99.32 \% \mathrm{Fe}, 0.18 \% \mathrm{C}, 0.02 \% \mathrm{Si}, 0.45 \% \mathrm{Mn}, 0.02 \% \mathrm{~S}$, and $0.01 \% \mathrm{P}$. The plate metal samples were embedded in epoxy resin, leaving a geometrical surface area of $1 \mathrm{~cm}^{2}$ exposed to the electrolyte and then polished with 600, 1000, 2000-grit paper in sequence, followed by ultrasonic cleaning and air-dried treatment prior to insertion in the test cell. The potentials were measured versus a kind of all solid-state $\mathrm{Ag} / \mathrm{AgCl}$ reference electrode and were calibrated using a saturated calomel electrode (SCE) after the experiments. A large mixed metal oxide (MMO) grid was used as the counter electrode.

The hydrostatic pressure apparatus is shown in Fig. 1. The hydrostatic pressure $P$ was controlled to $0.1,1,2,5$ and $10 \mathrm{MPa}$ during the CP process, respectively. The pressure is equivalent to a water depth of $0,100,200,500$ and $1000 \mathrm{~m}$. The temperature was controlled at $25 \pm 1{ }^{\circ} \mathrm{C}$ during the experimental process, in order to eliminate the influence of temperature changes on the CP process. The dissolved oxygen was of the natural concentration in seawater at the experimental temperature (approximately 6-7 $\mathrm{mg} \mathrm{L}^{-1}$ ). A galvanostatic polarization method was used to perform the $\mathrm{CP}$ experiments using a mean current density of $200 \mathrm{~mA} \mathrm{~m}^{-2}$. The working electrode was polarized for $168 \mathrm{~h}$.

In situ electrochemical measurements were carried out using an IM6e (ZAHNER, Germany) electrochemistry workstation after the galvanostatic polarization. A delay time of 40 minutes was set before the measurements were started in order to stabilize the electrode potential. A potentiodynamic polarization scan was performed at a scan rate of $0.1 \mathrm{mV} \mathrm{s}^{-1}$ in the range of $\pm 10 \mathrm{mV}$ at an open circuit potential (OCP). EIS measurements over a frequency range from $100 \mathrm{kHz}$ to $10 \mathrm{mHz}$ followed the potentiodynamic polarization scan. In order to resist the large interface impedance caused by the deposit formation and enhance the frequency response characteristics, a larger perturbation amplitude of $10 \mathrm{mV}$ at an OCP was employed,

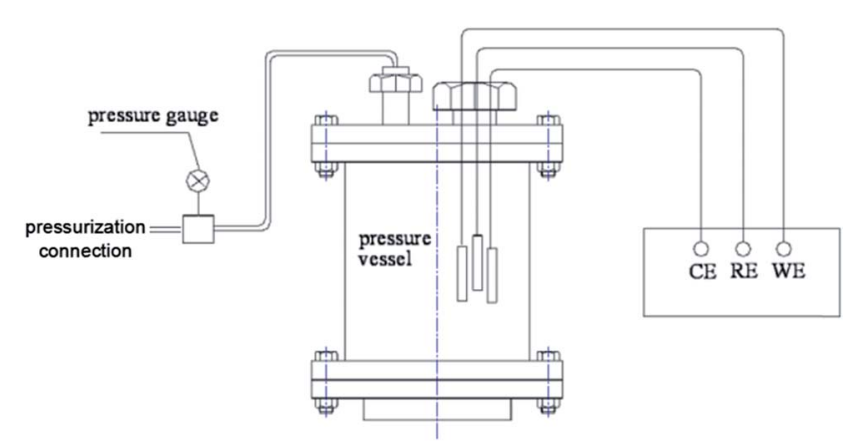

Fig. 1 A schematic of the electrochemical cell used for controlling the hydrostatic pressure. 
other than $5 \mathrm{mV}$ that is often used in conventional EIS measurements.

After the electrochemical measurements, the electrodes were taken out and rinsed with deionized water to clear away the salt (mainly of $\mathrm{NaCl}$ ). Then ex situ SEM observations using a JEOL JSM-6700F scanning electron microscope were performed to characterize the deposits, whose chemical compositions were analysed using energy dispersive X-ray spectroscopy (EDX). The EDX investigation zone was the entire exposed surface of the electrode. XRD was also involved to analyse the crystalline form of the deposits, performed on a D8 ADVANCE apparatus at a scanning rate of $4^{\circ} \mathrm{min}^{-1}$ and range of $10-80^{\circ}$.

\section{Results and discussion}

\subsection{Potential decay at various hydrostatic pressures}

The potential variation trends of the electrodes were recorded versus the polarized time under different hydrostatic pressures to investigate the protection status.

As shown in Fig. 2, almost the same variation trends were shown for the potential decay under different hydrostatic pressures. The electrodes potentials shifted negatively versus the protection time at the very beginning of the polarization of $60 \mathrm{~h}$, and then stabilized gradually. This was because of the formation of the calcareous deposits on the electrode surface, which can decrease the diffusion rate of oxygen to the metalsolution surface and inhibit the oxygen reduction reaction. Less oxygen diffusion to the steel surface and the accumulation of excess charge causes the steel potential to shifting negatively at the beginning of the polarization of $60 \mathrm{~h}$. When the potential was more negative than $-1.1 \mathrm{~V}$ ( $v s$. SCE), the non-diffusioncontrolled hydrogen evolution reaction became the dominant cathodic reaction, which was limited by the charge transfer. Therefore, the potential variations were not affected by the electrode surface status and the potential profiles almost overlapped with each other under different pressures during the later CP stage. This revealed that the protection potential of carbon steel was independent of the hydrostatic pressure.

\subsection{EIS measurements}

EIS measurements were performed in situ after the electrodes were polarized for $168 \mathrm{~h}$. As a comparison, electrodes without

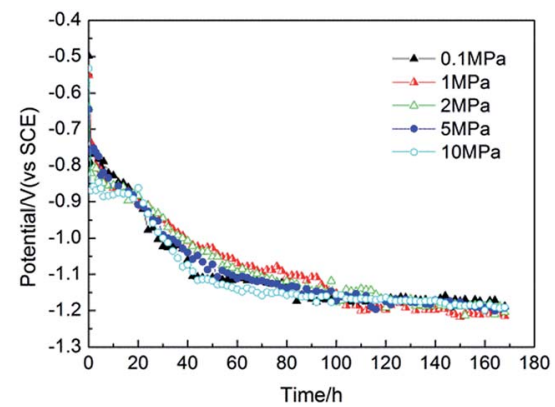

Fig. 2 The potential decay curves vs. time under various hydrostatic pressures under galvanostatic polarization. polarization (blank) were also measured under various hydrostatic pressures. The Nyquist diagrams of the electrodes under the different pressures are shown in Fig. 3.

For bare steel (blank), an obvious increase in the capacitive loop size with increasing hydrostatic pressure was observed (Fig. 3a), revealing an increase in the interfacial charge transfer rate. This may be caused by the higher activation energy under higher pressure. ${ }^{19}$ Nevertheless, the Nyquist diagrams of the electrodes after polarization showed more complex cases under the different hydrostatic pressures (Fig. 3b). The capacitive loop size initially increased with increasing pressure and then began to decrease, displaying a maximum value under a pressure of $2 \mathrm{MPa}$. All the Nyquist diagrams can be characterized by two capacitive loops with a supplementary loop appeared in the high frequency region. Additionally, the loop size in the high frequency region showed a relatively regular change, increasing with the hydrostatic pressure. This may be due to the higher electrochemical reaction resistance under high pressure, which was controlled by the activation energy. For all of the hydrostatic pressures studied, the capacitive loop observed at atmospheric pressure showed the smallest size. The variation of the loop size may be attributed to the increasing activation energy under higher pressure, on the other hand, it may be attributed to the formation of calcareous deposits with different compactness and protectiveness under the different pressures.

The equivalent circuit of impedance for bare steel can be described as a resistance corresponding the charge transfer
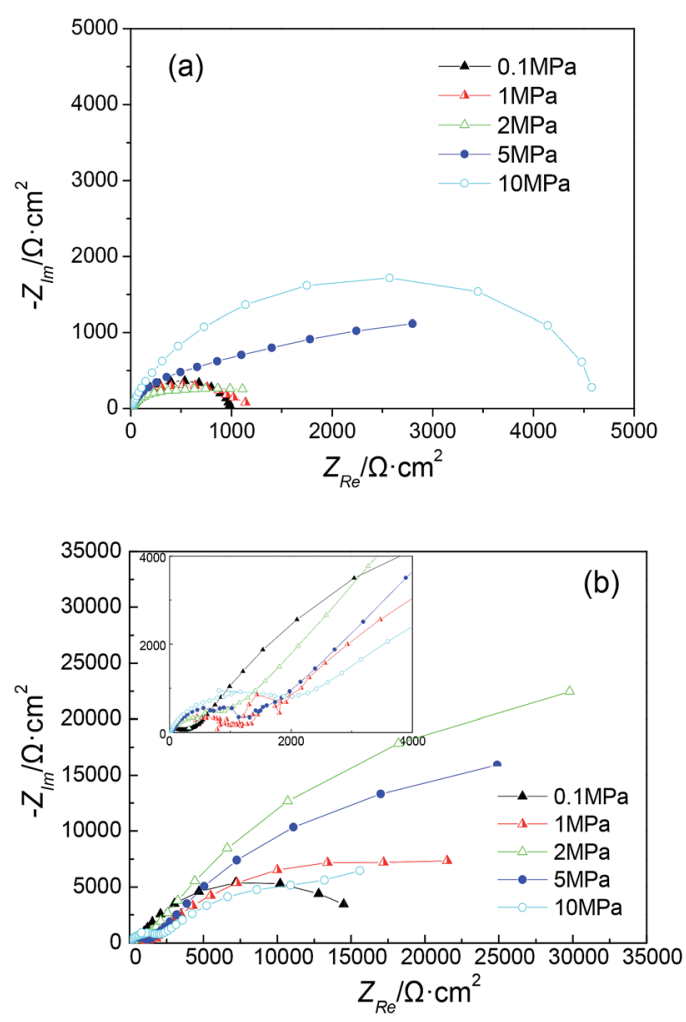

Fig. 3 Nyquist diagrams under various hydrostatic pressures: (a) without polarization (blank) and (b) with galvanostatic polarization for $168 \mathrm{~h}$. 
resistance $R_{\mathrm{ct}}$ in parallel to the double layer capacitance $C_{\mathrm{dl}}$, and these two elements are in series to an electrolyte resistance $R_{\mathrm{e}}$ (Fig. 4a).

Further, the impedance for the polarized electrodes can be illustrated using a five-element model (Fig. 4b), describing the porous calcareous deposits formation on the electrode surface. A resistance corresponding to the charge transfer resistance, $R_{\text {ct }}$, at the pores bottom is placed in parallel to a constant phase element, $\mathrm{CPE}_{1}$. The constant phase element (CPE) is defined in the impedance representation as:

$$
Z(\omega)=Z_{0}(\mathrm{j} \omega)^{-n}
$$

where $Z_{0}$ is the CPE constant, $\omega$ is the angular frequency (in rad $\left.\mathrm{s}^{-1}\right), \mathrm{j}^{2}=-1$, is the imaginary number and $n$ is the CPE exponent. ${ }^{21} \mathrm{CPE}_{1}$ is considered as a model of double layer capacitance $\left(R_{\mathrm{ct}}\right)$ like $\mathrm{H}_{2} \mathrm{O}$ and other ions adsorbed on the surface of steel and $\mathrm{CPE}_{2}$ as a model of calcareous deposits $\left(R_{\mathrm{f}}\right)$. The two elements of $\mathrm{CPE}_{1}$ and $R_{\mathrm{ct}}$ are in series to a resistance, $R_{\mathrm{f}}$, which corresponds to the finite conductivity of the electrolyte in the thin pores. The whole arrangement is placed in parallel to $\mathrm{CPE}_{2}$, reflecting the dielectric nature of the calcareous deposits (Fig. 4b). The fitting results for impedance under the various pressures are shown in Table 1.

As can been seen from the fitted results, the value of $R_{\mathrm{f}}$ increased under higher hydrostatic pressures and showed the smallest value under atmospheric pressure. One reason was that the transfer resistance of ions in the deposits thin pores increased under higher pressures, which may be due to the different deposit structures and compactness. Meanwhile, the charge transfer resistance $R_{\mathrm{ct}}$ increased greatly with increasing pressure. However, when the pressure was higher than $2 \mathrm{MPa}$, $R_{\text {ct }}$ began to decrease. The decreasing $R_{\text {ct }}$ under a certain high pressure revealed the decreasing protective properties of the calcareous deposits, which was constant with the research results of Tawns and Oakley. ${ }^{20}$ This may be attributed to the

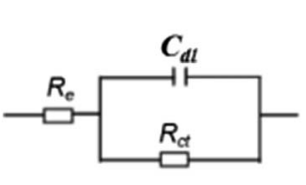

(a)

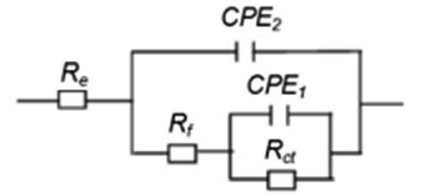

(b)
Fig. 4 Equivalent circuit diagram: (a) bare steel and (b) electrode covered by calcareous deposits. higher solubility of $\mathrm{CaCO}_{3}$ under higher pressures and less deposit generation, ${ }^{6}$ and it may also be due to the transformation of the crystal morphology under high pressure.

\subsection{LPR measurements}

Linear polarization resistance $\left(R_{\mathrm{p}}\right)$ is commonly used to calculate the corrosion current density of steel and a high value of $R_{\mathrm{p}}$ is generally accepted as a low corrosion rate. As the calcareous deposits are developed on the steel surface after CP, the corrosion rate of steel will decrease under the open circuit conditions due to the deposits protection. Meanwhile, the larger value of $R_{\mathrm{p}}$ indicates the lower corrosion rate, which corresponds to the more compact deposit precipitation and efficient protection.

LPR tests were performed in situ at the OCP and the value of $R_{\mathrm{p}}$ was obtained by fitting the linear polarization curve. The linear polarization resistance of bare steel for blank $\left(R_{\mathrm{p} 0}\right)$ was also obtained under various hydrostatic pressures (Fig. 5a).

Due to the increasing activation energy under high pressure, $R_{\mathrm{p} 0}$ increased linearly with an increase in the hydrostatic pressure. The value of $R_{\mathrm{p}}$ after polarization initially increased and then decreased, with a maximum value at $2 \mathrm{MPa}$. This was consistent with the results observed for the capacitive loop size in the EIS analysis.

In order to study the calcareous deposits influence on the polarization resistance of the steel electrode after $\mathrm{CP}$, the environmental background value is first deducted, which was induced by the ambient conditions of the different hydrostatic pressures. Hence, the protection factor $\left(F_{\mathrm{p}}\right)$ parameter was proposed to evaluate the calcareous deposits protection capability, ${ }^{22,23}$ defined by the equation $R_{\mathrm{p}} / R_{\mathrm{p} 0}-1$. It was considered that the $F_{\mathrm{p}}$ valve could present the growth of the steel polarization resistance induced by calcareous deposit precipitation when compared with bare steel with no deposits. The $F_{\mathrm{p}}$ valves of the electrodes under various pressures after $168 \mathrm{~h}$ of polarization are shown in Fig. 5b. The variation of $F_{\mathrm{p}}$ presents a similar trend to that observed for $R_{\mathrm{p}}$. However, there was an even smaller value of $F_{\mathrm{p}}$ at 5 and $10 \mathrm{MPa}$ than that found under ambient pressure, revealing a decrease in the protective properties of the calcareous deposits under certain high hydrostatic pressures.

\subsection{Morphological characteristics}

In order to investigate the calcareous deposits formation on the electrode surface during CP under various hydrostatic pressures, SEM observations were performed after $168 \mathrm{~h}$ of

Table 1 The EIS fitting results under various hydrostatic pressures

\begin{tabular}{llllr}
$\begin{array}{l}P \\
(\mathrm{MPa})\end{array}$ & $R_{\mathrm{s}}\left(\Omega \mathrm{cm}^{2}\right)$ & $\left.\mathrm{CPE}_{1}(\mu \mathrm{F} \mathrm{cm})^{-2}\right)\left(n_{1}\right)$ & $R_{\mathrm{f}}\left(\Omega \mathrm{cm}^{2}\right)$ & $\mathrm{CPE}_{2}\left(\mu \mathrm{F} \mathrm{cm} \mathrm{cm}^{-2}\right)\left(n_{2}\right)$ \\
\hline 0.1 & 1.498 & $120(0.7240)$ & 317 & $8.73(0.6553)$ \\
1 & 1.979 & $80.80(0.6327)$ & 1778 & $21.40(0.2988)$ \\
2 & 1.54 & $104(0.7507)$ & 1843 & $34.60(0.5982)$ \\
5 & 1.48 & $139(0.6745)$ & 1780 & $10.20(0.6487)$ \\
10 & 2.21 & $133.60(0.5143)$ & 1762 & $2.26(0.8482)$
\end{tabular}



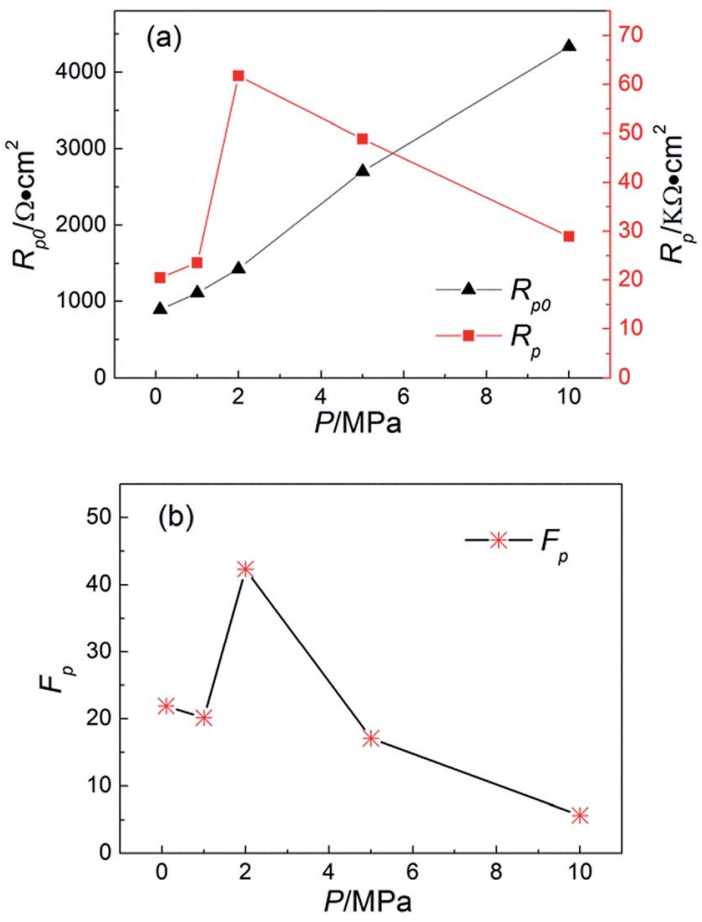

Fig. 5 (a) $R_{\mathrm{po}}$ and $R_{\mathrm{p}} v s$. $P$ and (b) $F_{\mathrm{p}} v s$. $P$ after galvanostatic polarization for $168 \mathrm{~h}$.

polarization and are shown in Fig. 6. All the electrodes surfaces were covered by calcareous deposits after CP under various pressures, while exhibiting different morphological characteristics. Generally, an increase in the deposited particles size have been observed with increasing hydrostatic pressure. The deposits show the typical cauliflower shape crystals of aragonite under most of the experimental pressure conditions studied. However, in addition to the aragonite (Fig. 6e, crystal-1), extraordinary crystals with a pyramidal shape (Fig. 6e, crystal2) were obtained under a pressure of $10 \mathrm{MPa}$.

The SEM images in Fig. 6 are at 2000 times magnification of the narrow focus ranges. A lower magnification of 500 times was further used to obtain a greater field of view, in order to confirm the crystals structures deposited on the whole electrodes surfaces and investigate the transformation mechanism for the two kinds of crystals observed under the different pressures. The coupled growth of the cauliflower and pyramidal crystals was revealed not only under a pressure of $10 \mathrm{MPa}$, but also at $5 \mathrm{MPa}$ (Fig. 7a). While the intergrowth crystals were not found under the other pressures studied. XRD analysis was performed to study the crystalline structures of the two kinds of deposits. The results illustrated that the pyramidal crystals were the dolomite of $\mathrm{CaMg}\left(\mathrm{CO}_{3}\right)_{2}$ and not the calcite of $\mathrm{CaCO}_{3}$ with a cubic structure, which normally forms at low temperature..$^{22,24}$ Generally, temperature was considered as the dominant factor for controlling the $\mathrm{CaCO}_{3}$ crystal form in the CP process. In addition, $\mathrm{CaCO}_{3}$ was generated in the form of aragonite when the temperature is higher than $20^{\circ} \mathrm{C}$, while calcite is formed at lower temperatures, ${ }^{6,22,25}$ while the other environmental parameters, such as dissolved oxygen, $\mathrm{pH}$ and salinity, have no
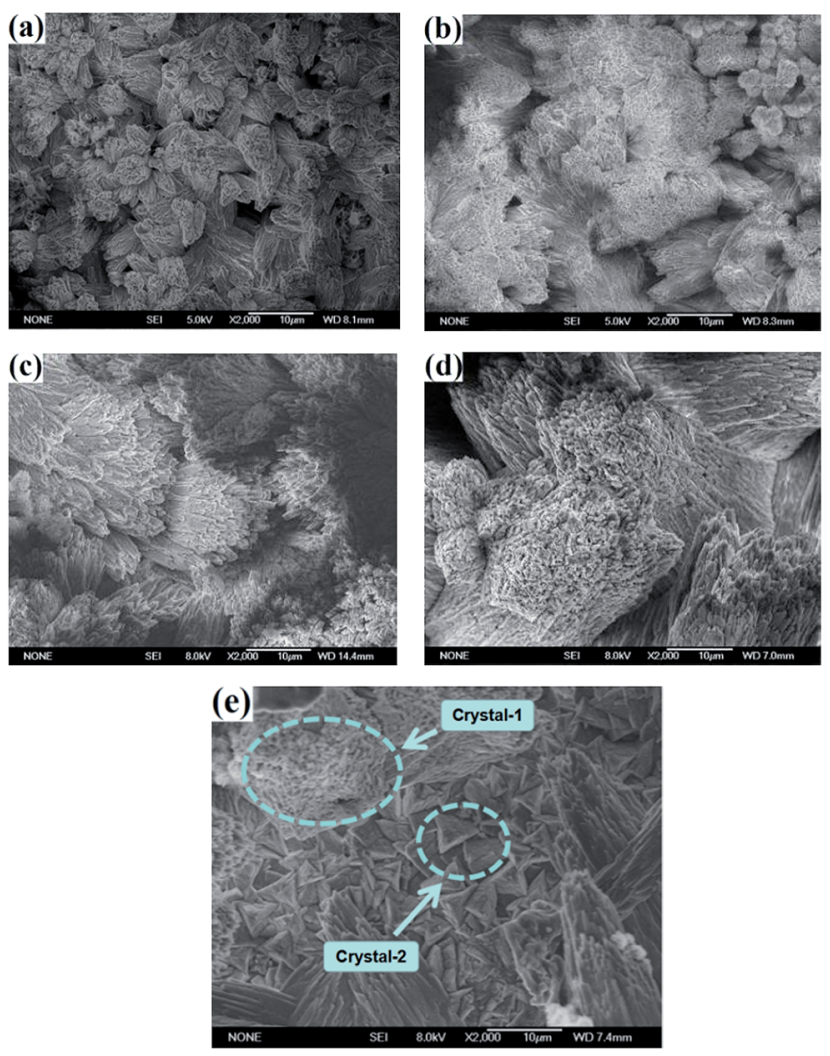

Fig. 6 SEM observations of the calcareous deposits under various hydrostatic pressures after galvanostatic polarization for $168 \mathrm{~h}$ : (a) $0.1 \mathrm{MPa}$, (b) $1 \mathrm{MPa}$, (c) $2 \mathrm{MPa}$, (d) $5 \mathrm{MPa}$ and (e) $10 \mathrm{MPa}$.
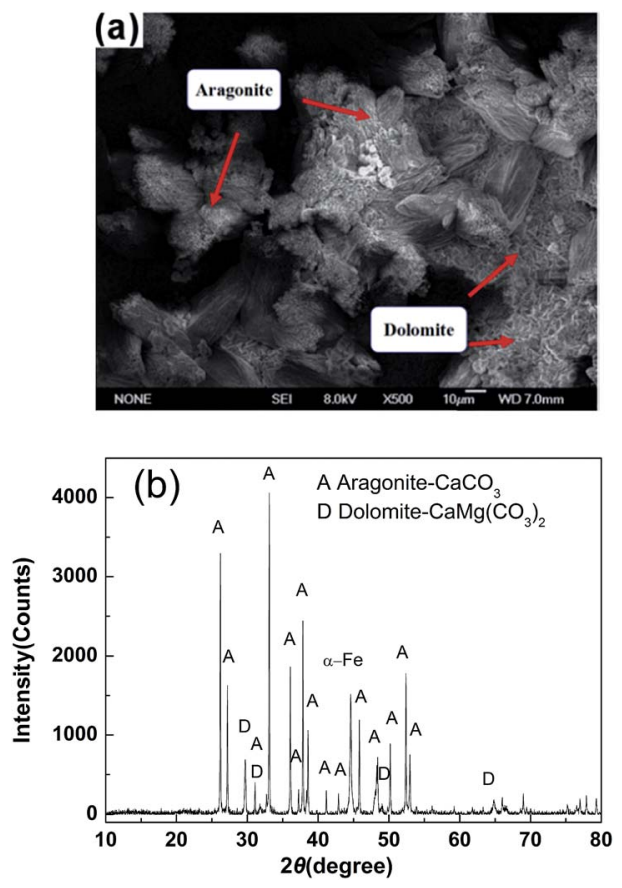

Fig. 7 (a) SEM observations and (b) XRD results for the calcareous deposits under $5 \mathrm{MPa}$ after $168 \mathrm{~h}$ of galvanostatic polarization. 
obvious influence on form of the $\mathrm{CaCO}_{3}$ crystals. Actually, the experiments here were all performed at $25{ }^{\circ} \mathrm{C}$. Therefore, it was believed that the formation of dolomite at ambient temperature was attributed to the high hydrostatic pressure. Additionally, it is generally believed that magnesium ions were easily adsorbed to the calcite surface and involved in the crystallization process, which would restrain the calcite growth. In addition, it had no effect on the growth of aragonite. ${ }^{25-29}$ However, it has been revealed distinctly that the magnesium ions participated in the crystallizing kinetics of aragonite under higher hydrostatic pressure in our experiments, which has been rarely reported before.

The reason for the formation of dolomite is believed to be due to the magnesium ions easily occupying the positions of the calcium ions in the $\mathrm{CaCO}_{3}$ lattice under high pressure due to their smaller ionic radius, leading to the crystallization of $\mathrm{CaMg}\left(\mathrm{CO}_{3}\right)_{2}$ (Fig. 8). Besides, it can be seen that the dolomite was covered by aragonite, revealing the dolomite was initially deposited and then the aragonite. Therefore, the magnesium ions only participate in the early stage of $\mathrm{CaCO}_{3}$ crystallization during the CP process. In the later stages, the crystallization of $\mathrm{CaCO}_{3}$ needs to overcome a smaller thermodynamic energy barrier due to the earlier deposited dolomite acting as a crystal nucleus.

Generally, the order degree $(\delta)$ is used to describe the arrangement of $\mathrm{Ca}^{2+}$ and $\mathrm{Mg}^{2+}$ in the dolomite crystal structure. There is the same number of $\mathrm{Ca}^{2+}$ and $\mathrm{Mg}^{2+}$ in an ideal dolomite structure, in which the $\mathrm{Ca}^{2+}, \mathrm{Mg}^{2+}$ and $\mathrm{CO}_{3}{ }^{2-}$ ions are alternately arranged in the $(00 i)$ direction. The $\delta$ can be expressed by the reflective intensity ratio of the (015) and (110) crystal planes, which is $\delta=I(015) / I(110) .{ }^{30}$ The calculated value of $\delta$ for the dolomite structure under $5 \mathrm{MPa}$ and $10 \mathrm{MPa}$ was 0.45 and 0.08, respectively, illustrating a decrease in $\delta$ under the higher hydrostatic pressures. This can be explained by the entropy increase in the process, which was caused by the increased disorder of the cation distribution in the dolomite crystal structure. The decrease in $\delta$ will be beneficial to decrease the free energy of the dolomite lattice under high pressure.

In order to investigate the atomic molar ratio of $\mathrm{Ca} / \mathrm{Mg}$ in the deposits formed under the different pressures, EDX was performed to verify the participating behavior of the magnesium ions during $\mathrm{CaCO}_{3}$ deposition under high pressure. The results

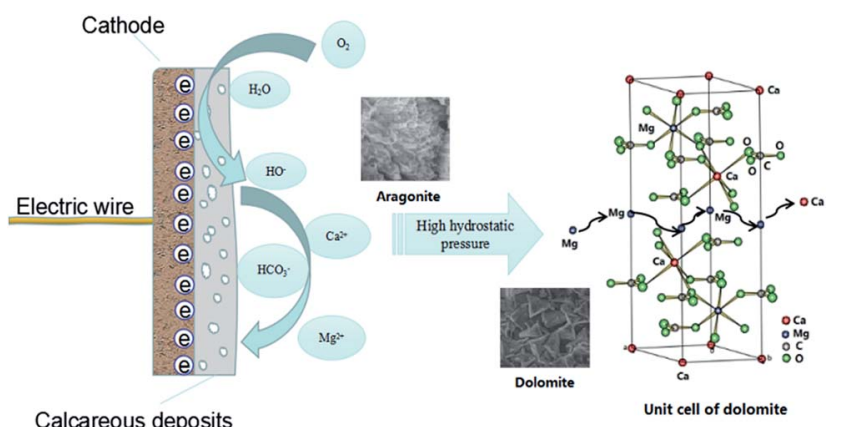

Fig. 8 A schematic of the transformation of calcium carbonate under high hydrostatic pressure.
Table 2 The atomic ratio of $\mathrm{Ca} / \mathrm{Mg}$ obtained from the EDX analyses under the various hydrostatic pressures studies

\begin{tabular}{llll}
\hline $\begin{array}{l}P \\
(\mathrm{MPa})\end{array}$ & $\begin{array}{l}\text { Ca fraction } \\
(\mathrm{mol} \%)\end{array}$ & $\begin{array}{l}\text { Mg fraction } \\
(\mathrm{mol} \%)\end{array}$ & $\begin{array}{l}\text { Atomic ratio } \\
\text { of } \mathrm{Ca} / \mathrm{Mg}\end{array}$ \\
\hline 0.1 & 16.85 & 0.07 & 240.71 \\
1 & 16.92 & 0.16 & 105.75 \\
2 & 17.38 & 0.24 & 74.42 \\
5 & 17.48 & 0.76 & 23.00 \\
10 & 21.70 & 1.55 & 14.00
\end{tabular}

are shown in Table 2. This reveals that the fraction of magnesium increased upon increasing the hydrostatic pressure. In addition, an obviously decrease in the $\mathrm{Ca} / \mathrm{Mg}$ ratio confirmed that more magnesium ions participated in the $\mathrm{CaCO}_{3}$ crystallization process under the higher pressures, leading to the deposition of dolomite and a decrease in $\delta$.

In summary, the morphology analysis echoed the results of the electrochemical measurements. Due to the higher solubility of the calcareous deposits under high hydrostatic pressure, a lower amount of deposits were generated on the steel surface. Additionally, the crystal transformation of the calcium carbonate from aragonite to dolomite caused a decrease in the deposits compactness and protectiveness. Both factors were attributed to the decrease in the capacitive loop size observed in EIS and $F_{\mathrm{p}}$ in the LPR results under high pressure. Therefore, a higher CP current density may be needed under a high hydrostatic pressure and in deep water.

\section{Conclusions}

In this paper, specific attention has been focused upon the influence of hydrostatic pressure on the CP process of carbon steel and also the mechanism for calcareous deposition. The CP process was monitored under various pressures. The electrochemical characteristics of the electrodes surfaces were studied after the $\mathrm{CP}$ process. The transformation of the calcium carbonate crystals from aragonite to dolomite was observed and confirmed under high hydrostatic pressures. The following conclusions are made:

(1) The protection potential of carbon steel was independent of the hydrostatic pressure in the investigated range from $0.1 \mathrm{MPa}$ to $10 \mathrm{MPa}$.

(2) The EIS results revealed that the capacitive loop size initially increased with increasing pressure due to the increasing activation energy needed and then began to decrease, which was attributed to the reduction of the deposit quality and protectiveness. The fitting results indicated a maximum value of the $R_{\mathrm{ct}}$ was obtained at $2 \mathrm{MPa}$.

(3) The LPR results demonstrated that the maximum protection factor $F_{\mathrm{p}}$ was obtained at $2 \mathrm{MPa}$, where the deposits exhibited the best protectiveness. When the pressure was higher than $5 \mathrm{MPa}$, the deposits protective capability was even worse than that found at ambient pressure.

(4) The morphology analysis echoed the results of the electrochemical measurements. The decrease in $R_{\mathrm{ct}}$ and $F_{\mathrm{p}}$ under 
high pressure was attributed to the higher solubility of $\mathrm{CaCO}_{3}$ and the transformation of its crystal form. The atomic molar ratio of $\mathrm{Ca} / \mathrm{Mg}$ in the deposits decreased with an increase in the hydrostatic pressure. When the pressure was higher than $5 \mathrm{MPa}$, the magnesium ions can occupy the positions of calcium ions in the $\mathrm{CaCO}_{3}$ lattice because of the smaller ionic radius, leading to the crystallization of $\mathrm{CaMg}\left(\mathrm{CO}_{3}\right)_{2}$. Due to the increase in entropy during the process and the decrease in the dolomite lattice free energy, the order degree $(\delta)$ of dolomite decreased under high pressure.

\section{Acknowledgements}

The authors gratefully acknowledge the financial support of this project by the National Natural Science Foundation of China (No. 41576076), Project of Shandong Province Higher Educational Science and Technology Program (No. J15LA62) and Doctoral Fund Project of Weifang University of Science and Technology (No. 2017BS07).

\section{References}

1 W. H. Hartt, Corrosion, 2012, 68, 1063-1075.

2 C. Rousseau, F. Baraud, L. Leleyter, M. Jeannin and O. Gil, Corros. Sci., 2010, 52, 2206-2218.

3 K. J. Kim and W. H. Hartt, Characteristics of cathodic protection and calcareous deposits for type 316L stainless steel in simulated deep sea conditions, in CORROSION 2006, NACE Conference, NACE International, Houston, TX, San Diego, U.S, March 12-16, 2006.

4 C. Barchiche, C. Deslouis, O. Gil, P. Refait and B. Tribollet, Electrochim. Acta, 2004, 49, 2833-2839.

5 L. Beaunier, C. Gabrielli, G. Poindessous, G. Maurin and R. Rosset, J. Electroanal. Chem., 2001, 501, 41-53.

6 J. F. Yan, R. E. White and R. B. Griffin, J. Electrochem. Soc., 1993, 140, 733-741.

7 K. E. Mantel, W. H. Hartt and T. Y. Chen, Corrosion, 1992, 48, 489-500.

8 R. U. Lee and J. Ambrose, Corrosion, 1988, 44, 887-891.

9 S. Chen and W. H. Hartt, Corrosion, 2002, 58, 38-48.

10 S. Chen, W. H. Hartt and W. Wolfson, Corrosion, 2003, 59, 721-732.

11 H. R. England and R. H. Heidersbach, The Effects of water depth on cathodic protection of steel in seawater, in Proceedings of the 13th Annual OTC, Offshore Technology Conference, OTC, Houston, TX, U.S, May 4-7, 1981, pp. 379-384.
12 K. P. Fischer, B. P. Espelid and B. P. Schei, A review of CP current demand and anode performance for deep water, in CORROSION 2001, NACE Conference, NACE International, Houston, TX, U.S, March 11-16, 2001.

13 M. R. Belmonte, J. T. P. Quiroz, B. V. Salas, M. M. Madrid, A. T. Acosta, J. P. Calderón and M. S. Wiener, Anti-Corros. Methods Mater., 2013, 60, 160-167.

14 C. Rousseau, F. Baraud, L. Leleyter, M. Jeannin and O. Gil, Electrochim. Acta, 2009, 55, 196-203.

15 C. Barchiche, C. Deslouis, O. Gil, S. Joiret, P. Refait and B. Tribollet, Electrochim. Acta, 2009, 54, 3580-3588.

16 A. Benedetti, L. Magagnin, F. Passaretti, E. Chelossi, M. Faimali and G. Montesperelli, Electrochim. Acta, 2009, 54, 6472-6478.

17 S. Rossi, P. L. Bonora, R. Pasinetti, L. Benedetti, E. Sacco and M. Draghetti, Corrosion, 1998, 54, 1018-1025.

18 S. N. Hu, T. Zhang, Y. W. Shao, G. Z. Meng and F. H. Wang, Anti-Corros. Methods Mater., 2011, 58, 238-244.

19 W. H. Thomason and K. P. Fischer, Cathodic protection of steel structures in deep water: A Review, in Proceedings of the 23rd Annual Offshore Technology Conference, Offshore Technology Conference OTC, Houston, TX, U.S, May 6-9, 1991, pp. 243-252.

20 A. Tawns and R. Oakley, Cathodic protection at a simulated depth of $2500 \mathrm{~m}$, in CORROSION 2000, NACE Conference, NACE International, Orlando, Houston, TX, U.S, March 2631, 2000.

21 B. Wang, M. Du, J. Zhang and C. J. Gao, Corros. Sci., 2011, 53, 353-361.

22 C. J. Li, M. Du, J. Qiu, J. Zhang and C. J. Gao, Acta Metall. Sin., 2014, 27, 131-139.

23 C. J. Li, M. Du and R. J. Gao, J. Ocean Univ. China, 2017, 16, 243-248.

24 C. Deslouis, D. Festy, O. Gil, G. Rius, B. Touzain and S. Tribollet, Electrochim. Acta, 1998, 43, 1891-1901.

25 S. H. Lin and S. C. Dexter, Corrosion, 1988, 44, 615-622.

26 T. Chen, A. Neville and M. Yuan, J. Cryst. Growth, 2005, 275, e1341-e1347.

27 A. Neville and A. P. Morizot, J. Cryst. Growth, 2002, 243, 490502.

28 C. Barchiche, C. Deslouis, D. Festy, O. Gil, P. Refait, S. Touzain and B. Tribollet, Electrochim. Acta, 2003, 48, 1645-1654.

29 C. Deslouis, D. Festy, O. Gil, V. Maillot, S. Touzain and B. Tribollet, Electrochim. Acta, 2000, 45, 1837-1901.

30 J. R. Goldsmith and D. L. Graf, J. Geol., 1958, 66, 678-693. 